\title{
An Osteoconductive, Osteoinductive, and Osteogenic Tissue-Engineered Product for Trauma and Orthopaedic Surgery: How Far Are We?
}

\author{
Wasim S. Khan, Faizal Rayan, Baljinder S. Dhinsa, and David Marsh \\ University College London Institute of Orthopaedics and Musculoskeletal Sciences, Royal National Orthopaedic Hospital, \\ Stanmore, Middlesex, London HA7 4LP, UK \\ Correspondence should be addressed to Wasim S. Khan, wasimkhan@doctors.org.uk
}

Received 24 June 2011; Accepted 28 August 2011

Academic Editor: Umile Longo

Copyright () 2012 Wasim S. Khan et al. This is an open access article distributed under the Creative Commons Attribution License, which permits unrestricted use, distribution, and reproduction in any medium, provided the original work is properly cited.

The management of large bone defects due to trauma, degenerative disease, congenital deformities, and tumor resection remains a complex issue for the orthopaedic reconstructive surgeons. The requirement is for an ideal bone replacement which is osteoconductive, osteoinductive, and osteogenic. Autologous bone grafts are still considered the gold standard for reconstruction of bone defects, but donor site morbidity and size limitations are major concern. The use of bioartificial bone tissues may help to overcome these problems. The reconstruction of large volume defects remains a challenge despite the success of reconstruction of small-to-moderate-sized bone defects using engineered bone tissues. The aim of this paper is to understand the principles of tissue engineering of bone and its clinical applications in reconstructive surgery.

\section{Introduction}

Bone is a highly vascularised tissue that constantly undergoes remodelling as a result of the balance between the activities of the osteoclasts and the osteoblasts, which allows adaptation to mechanical stresses, maintenance of bone health, and repair of small injuries. A recent study demonstrated that the coupling between osteoclastic bone resorption and osteoblastic bone formation is needed for bone homeostasis [1]. Because of the potential of bone to spontaneously regenerate, most small bone lesions, such as fractures, heal well with conventional therapy or surgery. During bone repair, the osteogenic process, under the influence of bonederived bioactive factors, commences after the inflammatory phase and is initiated by precursor cells from the periosteum adjacent to the fracture site. This generates hard callus by intramembranous bone formation. An autologous bone graft or bone substitute is often required to assist in the healing of an extensive traumatic or postsurgical bone defect and of osseous congenital deformities. The majority of bone formation, however, is by enchondral ossification of the soft callus that appears after infiltrated mesenchymal cells are induced to chondrogenesis. This improved understanding of repair, and regeneration has helped with the development of orthopaedic tissue engineering [2].

Historically, a variety of substitutes like celluloid, aluminium, gold, vitallium, tantalum, stainless steel, titanium, methyl methacrylate resins, polyethylene, silicone elastomers, and hydroxyapatite ceramics have been tried [3]. The main concerns with the use of these synthetic materials for bone reconstruction were their inability to vascularise, integrate, and undergo remodelling. This may result in structural failure of the implant under load or pathological changes in the surrounding bone, as seen in stress shielding [4]. The other issues are inflammatory scarring, neoproliferative reaction in the adjacent tissues and infection [5]. Because of their high osteoinductive potential and remodelling characteristics, bioactive substitutes such as demineralized bone matrix (allogeneic or xenogeneic) have shown promise, despite risk of disease transmission, as well as cost and availability [6]. This led to the evolution of tissue engineering techniques (biologically enhanced allografts, cell-based therapies, and gene-based therapies) to treat bone defects. 
Tissue engineering has been defined as the application of scientific principles to the design, construction, modification, and growth of living tissue using biomaterials, cells, and factors alone and in combination [7]. It involves the use of osteoconductive biomaterial scaffolds, with osteogenic cell populations and osteoinductive bioactive factors. The three components for tissue regeneration are (1) a degradable support or scaffold material; (2) bioactive factors, such as growth factors; (3) cells. The potential for bone tissue engineering therapies in clinical applications is exemplified by the clinical success of recombinant human bone morphogenetic protein-2 for the treatment of fractures [8].

The most promising primary tissue engineering strategies are (1) isolation of mesenchymal stems cells (MSCs), their ex vivo expansion, and seeding onto a scaffold to produce extracellular matrix (ECM) on the scaffold; (2) implantation of an acellular scaffold into the osseous defect [7]. Translation of this technology into practice requires an additional surgical procedure and the time lag for the bone graft to develop in vitro. A variety of novel ex vivo culture techniques have been designed to speed up the cellular production of ECM. Three principal ex vivo culture techniques utilized in bone tissue engineering are growth factor delivery, bioreactor systems, and gene therapy.

\section{Stem Cells}

A stem cell is a cell from the embryo, fetus, or adult that, under certain conditions, can reproduce for long periods. It can also give rise to specialized cells of body tissues and organs. The use of stem cells from the embryo or fetus has many ethical considerations, whereas the use of adult stem cells is generally well accepted by society. An adult stem cell is an undifferentiated or unspecialized cell present in differentiated tissue, which renews itself and becomes specialized to yield all of the cell types of the tissue from which it originated. Their progeny includes both new stem cells and committed progenitors with a more restricted differentiation potential. These progenitor cells in turn give rise to more differentiated cell types. The advantages of using stem cells rather than differentiated cells are a higher proliferative capacity, a higher regenerative potential over time, and the ability to allow revascularization of the avascular scaffold. Cells with osteoprogenitor features have been isolated from several tissues including periosteum, bone marrow, adipose tissue, and retina. The choice of source depends on accessibility, frequency of cells, and information of a particular cell system.

The sources of osteogenic human cells are primary cells, MSCs, embryonic stem cells, and induced pluripotent stem cells. We use cells after considering various factors like proliferation potential, osteogenicity, vasculogenicity, the homogeneity, and the phenotype stability, as well as cell safety after implantation. Differentiation of these cells can be obtained in vitro by changing the culture conditions after their expansion or by providing a new physiological microenvironment in the transplant area in vivo. The process involves the isolation of cells, with expansion in vitro culture and enrichment of appropriate cell type for enhanced bone formation, integration of the cells with host tissues, and expression of stable osteogenic phenotype.

Primary osteogenic cells can be derived from adult bone tissue and periosteum [9-14]. Due to donor site morbidity [15-17] and limited proliferation of primary cells, preparation of large autologous grafts from primary bone or periosteum-derived cells would be difficult [1820]. Research suggests that stem cells derived from bone marrow (BMSC) can be expanded for a significant number of cell doublings without cell senescence. The bone marrow is a reservoir of multipotent stem cells for mesenchymal tissues that can differentiate into fibroblastic, osteogenic, adipogenic, and reticular cells [21]. Expansion of stem cells using bone marrow aspirates depends on the donor age, volume, and technique. Although, it has been demonstrated that BMSCs can be culture expanded to large numbers [21], the osteogenic potential of BMSCs is maintained in older individuals [22], and appropriate conditions in vitro (e.g., culture on collagen substrate and growth factor supplementation of culture media) $[23,24]$ can help maintain cell differentiation potential $[25,26]$.

Adipose tissue stem cells (ASCs), due to their accessibility and potential for differentiation into osteogenic cells, represent another attractive source for bone tissue engineering. The number of cells produced by expansion is influenced by the tissue harvesting procedure, as well as the site of tissue harvesting, for example, arm, thigh, abdomen, and breast $[27,28]$. ASCs undergo similar mesenchymal lineage specific differentiation as BMSC. They also display similar surface antigen. The principle advantages of ASCs use are that they exist in abundant numbers, can be obtained with minimal donor morbidity, their proliferative capacity is unaffected by age, and they have the ability to regenerate bone in critical sized bone defects $[29,30]$.

Takahashi and Yamanaka [31] described the use of induced pluripotent stem (IPS) cells. The main concern in their conceptualisation was the risk of viral integration into the recipient genome. However, this was allayed by Okita et al. [32] producing virus-free IPS cells from embryonic fibroblasts. Another concern is the time frame taken for extended ex vivo culture to produce sufficient number of IPS cells from fibroblasts. Due to the availability in larger numbers, ASCs-derived IPS cells have the potential to address this issue.

Human embryonic stem cells (ESCs), isolated by Thomson et al. [33], have unlimited potential for proliferation in vitro and they can form any tissue in the body [34]. ESCs are commonly derived from the inner cell mass (ICM) of preimplantation stage blastocysts [34]. They can be either feeder dependent or independent. Due to the exposure of ESCs to animal components, they pose a serious risk of transmitting serious pathogens, and thus extensive screening is warranted prior to therapeutic applications.

Bone formation is further controlled by engineering adult stem cells to express genes like bone morphogenetic proteins (BMP2, BMP4, and BMP7), core binding factor $\alpha 1$ (Cbfa1), vascular endothelial growth factor (VEGF), and noggin [35]. In addition, human bone marrow osteoprogenitor cells can be isolated and enriched using monoclonal antibodies as selective markers, such as STRO-1, from a CD34+ 
fraction, SB-10 (reacting with ALCAM), SH-2 (reacting with CD105), and HOP-26 (reacting with CD63) [12, 13]. Fibroblast growth factor-2 (FGF-2) supplementation to the culture medium promotes cell proliferation and maintains their multilineage potential during expansion [14]. These cells can be combined with a suitable scaffold and used as an alternative to conventional bone autograft. The transplanted osteogenic stem cells can immediately begin to proliferate and lay down new bone matrix without removing the old matrix present in the autograft. The development of these cell-based technologies may result in decreased use of dead bone from conventional bone banks to induce new bone formation.

\section{Scaffold}

A key component in tissue engineering for bone regeneration is the scaffold that serves as a template for cell interactions and the formation of bone extra cellular matrix to provide structural support to the newly formed tissue $[6,7]$. Mesenchymal stem cells alone are unlikely to be sufficient for bone regeneration. Although marrow injections are simple and provide a reduced risk of morbidity, for large skeletal defects, a scaffold of appropriate shape, size, and mechanical competence is required for bone reconstruction [2]. The use of the scaffold or matrix is not only in controlling growth factor and cell delivery but also to provide a structural template to fill the tissue lesion [22]. Ideally, the scaffold should facilitate cell infiltration, matrix deposition, and cell attachment and consist of osteoconductive materials such as bone protein and hydroxyapatite. They should be able to allow load bearing and stimulate osteogenesis. The scaffolds could be naturally occurring, synthetic polymers, or bioceramics. Biodegradable scaffolds provide the initial structure and stability for tissue formation but degrade as tissue forms, providing background for matrix deposition and tissue growth [15-18]. They can be used alone or in combination with growth factors or osteoconductive materials [7].

The scaffold aims to mimic the extracellular matrix in a regenerating bone environment. It has to be informative to the cells as well as provide mechanical support [7]. A biomaterial should easily integrate with the adjacent bone and favour new tissue ingrowth (osteoconduction). It should allow colonization by the host blood vessels, be biocompatible and resorbable.

Various synthetic biomaterials like inorganic ceramics (e.g., hydroxyapatite, coralline-derived hydroxyapatite, tricalcium phosphate, calcium sulphates, glass ceramics, calcium phosphate-based cements, and bioglass), metals, and synthetic biodegradable polymer composites have been investigated for their potential as bone scaffold materials. Calcium-phosphate ceramics were introduced more than 40 years ago as bone substitutes. The most common types of calcium-phosphate materials investigated for synthetic bone scaffold development are hydroxyapatite (HA), tricalcium phosphate (TCP), biphasic calcium phosphates (BCP), and bioglasses. From a functional perspective, you can divide these into rapidly resorbing, slowly resorbing, and injectable ceramics. TCP is a classic example of rapidly resorbing ceramic; it has got greater solubility than HA. Due to their porosity, TCP granules are a better option than the bulk form [35], while HA resorbs slowly, which is clinically a disadvantage. Composite modification of HA matrices has been tried to increase the resorption, for example, composite of HA and calcium carbonate and BCP. Injectable calcium phosphate cements were also in vogue. They are mainly composed of $\alpha$-TCP, dibasic dicalcium phosphate and tetra calcium phosphate. Clinically, they have been used in treatment of distal radius fractures [35-37]. The main disadvantage of their clinical relevance as synthetic bone scaffolds is due to their inherent brittleness [38].

However, due to their physiochemical properties, biocompatibility, and controllable biodegradability, polymers have emerged as the principal material in bone tissue engineering. The most frequently investigated polymers are polylactic acid (PLA) and polyglycolic acid (PGA) [39-41]. Numerous polymers were used as scaffold materials in the past decade for bone regeneration like poly(a-hydroxy esters), poly(ethylene glycol), polydioxanone, poly(orthoesters), polyanhydrides, polyurethanes, and poly(propylene fumarate) [42]. To gain more control over the degradation rate, hydrophobicity, crystallinity, and biological functionality, researchers designed composite polymers in a chemical process called copolymerization where multiple constituents are combined resulting in a new material with desirable properties from each constituent [43]. Undoubtedly, the most commonly utilized copolymer for bioactive molecule encapsulation and release for bone tissue engineering is the copolymer poly(lactic acid-coglycolic acid) (PLGA) [43]. The inherent deficiency of the compressive modulus in polymers may be reduced through integration of high modulus micro- and/or nanoscale constituents within the polymer matrix [43]. The most commonly researched constituent in polymer composites for bone scaffolds is micro- or nanoscale HA particles [44, 45]. Tensile strength, modulus, and crack resistance of polymers are improved by dispersing high modulus micro- or nanoscale constituents $[15-17,46]$. Whereas drawbacks for utilizing natural polymers like collagen, glycosaminoglycan, fibrin, and silk include infection, fixed degradation rates, and immunogenicity. Gel-like matrices such as fibrin have been used for cell immobilization in combination with other scaffolds [47]. Currently, computer-assisted design/computerassisted manufacturing (CAD/CAM) and rapid prototyping techniques allow the generation of custom-made scaffolds for cell delivery that fit into certain bone defects $[22,48]$.

There is a large number of osteogenic proteins that stimulate proliferation and differentiation of osteogenic cells in vitro and in vivo. Some osteogenic factors have been cloned and are commercially available as recombinant proteins. The most potent osteoinductive factors are bone morphogenetic protein (BMP). BMPs belong to the TGF- $\beta$ family [49]. BMP-2 and BMP-7 are being clinically applied for fractures and nonunions $[8,50]$. They have a short half-life, so local BMP delivery systems either require a high concentration bolus dose or sustained delivery for bone tissue engineering [51]. However, high BMP concentrations are associated 
with increased osteoclastic activity and bone resorption [23, 24]. Other options are the direct implantation of a carrier that allows slow release or gene-based therapies, where a transgene for BMP expression is delivered to progenitor cells $[52,53]$. Collagen carriers have historically been and remain the primary delivery system for BMPs to clinical defects. Because collagen has got poor BMP retention, higher BMP drug concentrations are required. Another concern is the potential for an immunogenic response or disease transfer from animal-derived collagen (e.g., variants of CreutzfeldtJacob disease or other prion-related diseases) [54]. A number of synthetic biomaterials have been proposed for BMP, such as inorganic ceramics, metals, and synthetic biodegradable polymers. Many of these materials are poorly biodegradable and radiopaque, whereas synthetic biodegradable polymers are mouldable and radiolucent. These characteristics make it easier to assess radiographic growth $[55,56]$.

Tissue engineering strategies aim at controlling the behaviour of individual cells to stimulate tissue formation. Currently, tissue-engineered bone is constructed using a perfusion bioreactor in vitro. Several different bioreactors have been investigated for tissue-engineering applications. Among these bioreactors are the spinner flask rotating wall vessel reactors and the flow perfusion culture bioreactors. Flow perfusion culture offers several advantages, notably the ability to mitigate both external and internal diffusional limitations as well as to apply mechanical stress to the cultured cells. In the perfusion culture, fluid flow can exert shear stress on the cells seeded on scaffold, improving the mass transport of the cells. Bioreactor systems of a variety of designs have also been utilized to enhance the in vitro performance of osteogenic cells before implantation. Bioreactors simulate the $3 \mathrm{D}$ dynamic and mechanical in vivo environment and are designed to provide cells seeded deep within a scaffold with all necessary nutrients and biological cues to survive, proliferate, differentiate, and produce ECM [57, 58]. Sikavitsas et al. [59] demonstrated proof of this concept by showing that after 16 days of culture, MSCproduced ECM was uniformly distributed in 3D scaffolds cultured in a flow profusion bioreactor, whereas the ECM was limited to the periphery in the case of standard static culture condition. Janssen et al. [60] demonstrated that direct perfusion bioreactor system is capable of producing clinically relevant volumes of tissue-engineered bone in a bioreactor system, which can be monitored on line during cultivation.

In summary, many factors can influence the osteoblastic differentiation of marrow stromal cells when cultivated on three-dimensional tissue engineering scaffolds. In creating ideal bone tissue engineering constructs consisting of a combination of a scaffold, cells, and bioactive factors, a flow perfusion bioreactor is a much more suitable culture environment than static culture in well plates. The bioreactor eliminates mass transport limitations to the scaffold interior and provides mechanical stimulation to the seeded cells through fluid shear [61]. Scaffold properties such as pore size impact cell differentiation, especially in flow perfusion culture. In addition, the bone-like ECM created by the in vitro culture of marrow stromal cells on porous scaffolds creates an osteoinductive environment for the differentiation of other marrow stromal cell populations. Therefore, bone tissue engineering constructs created by in vitro culture have excellent potential for bone regeneration applications in the clinical setting.

\section{Clinical Outcomes}

In literature, there are numerous studies demonstrating the effectiveness of bone tissue engineering techniques in the rodent model; however, little has been produced demonstrating its role in reconstructing osseous defects in larger animals. Petite et al. [62] investigated the role of in vitro expanded MSCs on a coral scaffold in large segmental bone defects in sheep. The study compared this technique with using the scaffold alone and the use of scaffolds with fresh bone marrow. With the tissue-engineered technique, clinical union was demonstrated in three out of seven bone defects, compared with no evidence of clinical union in any of the defects that were left empty or filled with scaffold alone.

With regards to the use of tissue engineering strategies in human bone reconstruction, published literature is sparse. Schimming and Schmelzeisen [63] reported the use of periosteum-derived tissue-engineered bone for the augmentation of the posterior maxilla. At three-month followup, eighteen out of twenty-seven patients demonstrated an excellent clinical, radiological, and histological outcome. Marcacci et al. [64] reported the use of ex vivo expanded bone marrow-derived MSCs implanted on a macroporous hydroxyapatite scaffold in four patients with large bone defects. One patient had a four-centimetre bone defect of the mid-diaphysis of the tibia following unsuccessful bone lengthening, another had traumatic loss of four centimetres of bone from the distal diaphysis of the ulna, the third patient had a seven centimetres bone defect of the humerus following a fracture and the final patient had six centimetres of traumatic bone loss from the ulna. The scaffolds were of the shape and size to fit each defect when implanted. External fixation was used for mechanical stability and removed after 6.5 months for the first patient, at 6 months for the second patient, at 13 months in the fourth patient, and 7 months for the final patient. Abundant callus formation along the implants and good integration with the host bones were evident on radiography and computed tomography after 1-2 months. At a minimum of 1-year followup, good integration of the implant to host bone was evident. All the patients reported favourable limb function outcome [64].

\section{Conclusion}

The use of tissue engineering for the reconstruction of bone defects has exciting potential; however, there is much work to be done before this strategy can be considered a serious clinical option [65-71]. The majority of research in MSC-based bone reconstruction has looked at isolation and expansion in vitro of MSCs, their delivery to defect sites and techniques to improve proliferation potential, and direct the MSCs towards osteogenesis using the appropriate factors [72-86]. 
Whilst animal studies have proven to show some success, the use of tissue engineering to repair bone defects in humans remains a challenge with limited clinical data. The reason for the perceived failure of these strategies in humans is thought to lie with an inadequate vascular supply, leading to cell death of implanted cells. There have also been concerns raised by the poor resorbability of the scaffolds and instability of the scaffold fixation. Whilst much work has been done on the factors involved in tissue engineering, more study is required to improve the key factor of cell survival in human models, such as improving nutrient and oxygen supply. Eventually, randomised controlled trials will be required to determine the effectiveness of tissue engineering approaches to bone reconstruction in humans before clinical use can be considered a viable option.

\section{References}

[1] Y. Tang, X. Wu, W. Lei et al., “TGF-beta 1-induced migration of bone mesenchymal stem cells couples bone resorption with formation," Nature Medicine, vol. 15, no. 7, pp. 757-765, 2009.

[2] M. C. Kruyt, S. M. van Gaalen, F. C. Oner, A. J. Verbout, J. D. De Bruijn, and W. J. A. Dhert, "Bone tissue engineering and spinal fusion: the potential of hybrid constructs by combining osteoprogenitor cells and scaffolds," Biomaterials, vol. 25, no. 9, pp. 1463-1473, 2004.

[3] M. Artico, L. Ferrante, F. S. Pastore et al., "Bone autografting of the calvaria and craniofacial skeleton: historical background, surgical results in a series of 15 patients, and review of the literature," Surgical Neurology, vol. 60, no. 1, pp. 71-79, 2003.

[4] Y. T. Konttinen, D. Zhao, A. Beklen et al., "The microenvironment around total hip replacement prostheses," Clinical Orthopaedics and Related Research, no. 430, pp. 28-38, 2005.

[5] L. G. Mercuri and A. Giobbie-Hurder, "Long-term outcomes after total alloplastic temporomandibular joint reconstruction following exposure to failed materials," Journal of Oral and Maxillofacial Surgery, vol. 62, no. 9, pp. 1088-1096, 2004.

[6] A. M. Pou, "Update on new biomaterials and their use in reconstructive surgery," Current Opinion in Otolaryngology and Head and Neck Surgery, vol. 11, no. 4, pp. 240-244, 2003.

[7] R. Langer and J. P. Vacanti, "Tissue engineering," Science, vol. 260, no. 5110, pp. 920-926, 1993.

[8] S. Govender, C. Csimma, H. K. Genant et al., "Recombinant human bone morphogenetic protein-2 for treatment of open tibial fractures: a prospective, controlled, randomized study of four hundred and fifty patients," Journal of Bone and Joint Surgery: Series A, vol. 84, no. 12, pp. 2123-2134, 2002.

[9] J. M. Mailhot and J. L. Borke, "An isolation and in vitro culturing method for human intraoral bone cells derived from dental implant preparation sites," Clinical Oral Implants Research, vol. 9, no. 1, pp. 43-50, 1998.

[10] D. W. Hutmacher and M. Sittinger, "Periosteal cells in bone tissue engineering," Tissue Engineering, vol. 9, no. 1, pp. S45S64, 2003.

[11] N. Kimelman, G. Pelled, G. A. Helm, J. Huard, E. M. Schwarz, and D. Gazit, "Review: gene- and stem cell-based therapeutics for bone regeneration and repair," Tissue Engineering, vol. 13, no. 6, pp. 1135-1150, 2007.

[12] D. A. Stewart, D. Guo, J. Luider et al., "Factors predicting engraftment of autologous blood stem cells: CD34+ subsets inferior to the total CD34+ cell dose," Bone Marrow Transplantation, vol. 23, no. 12, pp. 1237-1243, 1999.
[13] K. A. Partridge and R. O. C. Oreffo, "Gene delivery in bone tissue engineering: progress and prospects using viral and nonviral strategies," Tissue Engineering, vol. 10, no. 1-2, pp. 295-307, 2004.

[14] R. Cancedda, G. Bianchi, A. Derubeis, and R. Quarto, "Cell therapy for bone disease: a review of current status," Stem Cells, vol. 21, no. 5, pp. 610-619, 2003.

[15] B. D. Porter, J. B. Oldham, S. L. He et al., "Mechanical properties of a biodegradable bone regeneration scaffold," Journal of Biomechanical Engineering, vol. 122, no. 3, pp. 286$288,2000$.

[16] J. Wang, L. Qu, X. Meng, J. Gao, H. Li, and G. Wen, "Preparation and biological properties of PLLA/ $\beta$-TCP composites reinforced by chitosan fibers," Biomedical Materials, vol. 3, no. 2, Article ID 025004, 2008.

[17] H. Yu, H. W. Matthew, P. H. Wooley, and S. Y. Yang, "Effect of porosity and pore size on microstructures and mechanical properties of poly-epsilon-caprolactone- hydroxyapatite composites," Journal of Biomedical Materials Research: Part B, vol. 86, no. 2, pp. 541-547, 2008.

[18] P. V. Giannoudis, H. Dinopoulos, and E. Tsiridis, "Bone substitutes: an update," Injury, vol. 36, pp. S20-S27, 2005.

[19] E. Ahlmann, M. Patzakis, N. Roidis, L. Shepherd, and P. Holtom, "Comparison of anterior and posterior iliac crest bone grafts in terms of harvest-site morbidity and functional outcomes," Journal of Bone and Joint Surgery, vol. 84, no. 5, pp. 716-720, 2002.

[20] J. Li and H. L. Wang, "Common implant-related advanced bone grafting complications: classification, etiology, and management," Implant Dentistry, vol. 17, no. 4, pp. 389-401, 2008.

[21] P. Bianco, M. Riminucci, S. Gronthos, and P. G. Robey, "Bone marrow stromal stem cells: nature, biology, and potential applications," Stem Cells, vol. 19, no. 3, pp. 180-192, 2001.

[22] S. Yang, K. F. Leong, Z. Du, and C. K. Chua, "The design of scaffolds for use in tissue engineering. Part I. Traditional factors," Tissue Engineering, vol. 7, no. 6, pp. 679-689, 2001.

[23] K. Itoh, N. Udagawa, T. Katagiri et al., "Bone morphogenetic protein 2 stimulates osteoclast differentiation and survival supported by receptor activator of nuclear factor- $\kappa \mathrm{B}$ ligand," Endocrinology, vol. 142, no. 8, pp. 3656-3662, 2001.

[24] H. Kaneko, T. Arakawa, H. Mano et al., "Direct stimulation of osteoclastic bone resorption by bone morphogenetic protein (BMP)-2 and expression of BMP receptors in mature osteoclasts," Bone, vol. 27, no. 4, pp. 479-486, 2000.

[25] A. I. Caplan, "Adult mesenchymal stem cells for tissue engineering versus regenerative medicine," Journal of Cellular Physiology, vol. 213, no. 2, pp. 341-347, 2007.

[26] J. R. Mauney, D. L. Kaplan, and V. Volloch, "Matrix-mediated retention of osteogenic differentiation potential by human adult bone marrow stromal cells during ex vivo expansion," Biomaterials, vol. 25, no. 16, pp. 3233-3243, 2004.

[27] J. M. Gimble, A. J. Katz, and B. A. Bunnell, "Adipose-derived stem cells for regenerative medicine," Circulation Research, vol. 100, no. 9, pp. 1249-1260, 2007.

[28] P. A. Zuk, M. Zhu, H. Mizuno et al., "Multilineage cells from human adipose tissue: implications for cell-based therapies," Tissue Engineering, vol. 7, no. 2, pp. 211-228, 2001.

[29] C. M. Cowan, Y. Y. Shi, O. O. Aalami et al., "Adipose-derived adult stromal cells heal critical-size mouse calvarial defects," Nature Biotechnology, vol. 22, no. 5, pp. 560-567, 2004.

[30] E. Yoon, S. Dhar, D. E. Chun, N. A. Gharibjanian, and G. R. D. Evans, "In vivo osteogenic potential of human adipose-derived stem cells/poly lactide-co-glycolic acid constructs for bone 
regeneration in a rat critical-sized calvarial defect model," Tissue Engineering, vol. 13, no. 3, pp. 619-627, 2007.

[31] K. Takahashi and S. Yamanaka, "Induction of pluripotent stem cells from mouse embryonic and adult fibroblast cultures by defined factors," Cell, vol. 126, no. 4, pp. 663-676, 2006.

[32] K. Okita, M. Nakagawa, H. Hyenjong, T. Ichisaka, and S. Yamanaka, "Generation of mouse induced pluripotent stem cells without viral vectors," Science, vol. 322, no. 5903, pp. 949953, 2008.

[33] J. A. Thomson, J. Itskovitz-Eldor, S. S. Shapiro et al., "Embryonic stem cell lines derived from human blastocysts," Science, vol. 282, no. 5391, pp. 1145-1147, 1998.

[34] L. M. Hoffman and M. K. Carpenter, "Characterization and culture of human embryonic stem cells," Nature Biotechnology, vol. 23, no. 6, pp. 699-708, 2005.

[35] J. E. Fleming Jr., C. N. Cornell, and G. F. Muschler, "Bone cells and matrices in orthopedic tissue engineering," Orthopedic Clinics of North America, vol. 31, no. 3, pp. 357-374, 2000.

[36] J. B. Jupiter, S. Winters, S. Sigman et al., "Repair of five distal radius fractures with an investigational cancellous bone cement: a preliminary report," Journal of Orthopaedic Trauma, vol. 11, no. 2, pp. 110-116, 1997.

[37] P. Kopylov, K. Jonsson, K. G. Thorngren, and P. Aspenberg, "Injectable calcium phosphate in the treatment of distal radial fractures," Journal of Hand Surgery, vol. 21, no. 6, pp. 768-771, 1996.

[38] K. Rezwan, Q. Z. Chen, J. J. Blaker, and A. R. Boccaccini, "Biodegradable and bioactive porous polymer/inorganic composite scaffolds for bone tissue engineering," Biomaterials, vol. 27, no. 18, pp. 3413-3431, 2006.

[39] A. G. Mikos, Y. Bao, L. G. Cima, D. E. Ingber, J. P. Vacanti, and R. Langer, "Preparation of poly(glycolic acid) bonded fiber structures for cell attachment and transplantation," Journal of Biomedical Materials Research, vol. 27, no. 2, pp. 183-189, 1993.

[40] A. G. Mikos, G. Sarakinos, S. M. Leite, J. P. Vacanti, and R. Langer, "Laminated three-dimensional biodegradable foams for use in tissue engineering," Biomaterials, vol. 14, no. 5, pp. 323-330, 1993.

[41] D. J. Mooney, D. F. Baldwin, N. P. Suh, J. P. Vacanti, and R. Langer, "Novel approach to fabricate porous sponges of poly(D,L-lactic-co-glycolic acid) without the use of organic solvents," Biomaterials, vol. 17, no. 14, pp. 1417-1422, 1996.

[42] C. R. Kothapalli, M. T. Shaw, and M. Wei, "Biodegradable HAPLA 3-D porous scaffolds: effect of nano-sized filler content on scaffold properties," Acta Biomaterialia, vol. 1, no. 6, pp. 653-662, 2005.

[43] J. R. Porter, T. T. Ruckh, and K. C. Popat, "Bone tissue engineering: a review in bone biomimetics and drug delivery strategies," Biotechnology Progress, vol. 25, no. 6, pp. 15391560, 2009.

[44] E. M. Christenson, K. S. Anseth, J. J. J. P. Van den Beucken et al., "Nanobiomaterial applications in orthopedics," Journal of Orthopaedic Research, vol. 25, no. 1, pp. 11-22, 2007.

[45] J. Chlopek, A. Morawska-Chochol, G. Bajor et al., "The influence of carbon fibres on the resorption time and mechanical properties of the lactide-glycolide co-polymer," Journal of Biomaterials Science, vol. 18, no. 11, pp. 1355-1368, 2007.

[46] J. D. Kaufman, J. Song, and C. M. Klapperich, "Nanomechanical analysis of bone tissue engineering scaffolds," Journal of Biomedical Materials Research: Part A, vol. 81, no. 3, pp. 611623, 2007.
[47] U. Kneser, D. J. Schaefer, E. Polykandriotis, and R. E. Horch, "Tissue engineering of bone: the reconstructive surgeon's point of view," Journal of Cellular and Molecular Medicine, vol. 10, no. 1, pp. 7-19, 2006.

[48] J. T. Schantz, D. W. Hutmacher, C. X. F. Lam et al., "Repair of calvarial defects with customised tissue-engineered bone grafts II. Evaluation of cellular efficiency and efficacy in vivo," Tissue Engineering, vol. 9, no. 1, pp. S127-S139, 2003.

[49] A. H. Reddi, "Morphogenesis and tissue engineering of bone and cartilage: inductive signals, stem cells, and biomimetic biomaterials," Tissue Engineering, vol. 6, no. 4, pp. 351-359, 2000.

[50] R. Dimitriou, Z. Dahabreh, E. Katsoulis, S. J. Matthews, T. Branfoot, and P. V. Giannoudis, "Application of recombinant BMP-7 on persistent upper and lower limb non-unions," Injury, vol. 36, no. 4, pp. S51-S59, 2005.

[51] N. Y. Yu, A. Schindeler, D. G. Little, and A. J. Ruys, "Biodegradable poly(alpha-hydroxy acid) polymer scaffolds for bone tissue engineering," Journal of Biomedical Materials Research: Part B, vol. 93, no. 1, pp. 285-295, 2010.

[52] K. Gonda, T. Nakaoka, K. Yoshimura, Y. Otawara-Hamamoto, and K. Harrii, "Heterotopic ossification of degenerating rat skeletal muscle induced by adenovirus-mediated transfer of bone morphogenetic protein-2 gene," Journal of Bone and Mineral Research, vol. 15, no. 6, pp. 1056-1065, 2000.

[53] X. Zhang, C. Xie, A. S. Lin et al., "Periosteal progenitor cell fate in segmental cortical bone graft transplantations: implications for functional tissue engineering," Journal of Bone and Mineral Research, vol. 20, no. 12, pp. 2124-2137, 2005.

[54] D. Olsen, C. Yang, M. Bodo et al., "Recombinant collagen and gelatin for drug delivery," Advanced Drug Delivery Reviews, vol. 55, no. 12, pp. 1547-1567, 2003.

[55] N. Matsushita, H. Terai, T. Okada et al., "A new bone-inducing biodegradable porous beta-tricalcium phosphate," Journal of Biomedical Materials Research, vol. 70, no. 3, pp. 450-458, 2004.

[56] N. Murakami, N. Saito, H. Horiuchi, T. Okada, K. Nozaki, and K. Takaoka, "Repair of segmental defects in rabbit humeri with titanium fiber mesh cylinders containing recombinant human bone morphogenetic protein-2 (rhBMP-2) and a synthetic polymer," Journal of Biomedical Materials Research, vol. 62, no. 2, pp. 169-174, 2002.

[57] V. I. Sikavitsas, G. N. Bancroft, and A. G. Mikos, "Formation of three-dimensional cell/polymer constructs for bone tissue engineering in a spinner flask and a rotating wall vessel bioreactor," Journal of Biomedical Materials Research, vol. 62, no. 1, pp. 136-148, 2002.

[58] G. N. Bancroft, V. I. Sikavitsas, and A. G. Mikos, "Design of a flow perfusion bioreactor system for bone tissue-engineering applications," Tissue Engineering, vol. 9, no. 3, pp. 549-554, 2003.

[59] V. I. Sikavitsas, G. N. Bancroft, J. J. Lemoine, M. A. K. Liebschner, M. Dauner, and A. G. Mikos, "Flow perfusion enhances the calcified matrix deposition of marrow stromal cells in biodegradable nonwoven fiber mesh scaffolds," Annals of Biomedical Engineering, vol. 33, no. 1, pp. 63-70, 2005.

[60] F. W. Janssen, J. Oostra, A. Van Oorschot, and C. A. Van Blitterswijk, "A perfusion bioreactor system capable of producing clinically relevant volumes of tissue-engineered bone: in vivo bone formation showing proof of concept," Biomaterials, vol. 27, no. 3, pp. 315-323, 2006.

[61] H. L. Holtorf, J. A. Jansen, and A. G. Mikos, "Modulation of cell differentiation in bone tissue engineering constructs 
cultured in a bioreactor," Advances in Experimental Medicine and Biology, vol. 585, pp. 225-241, 2006.

[62] H. Petite, V. Viateau, W. Bensaïd et al., "Tissue-engineered bone regeneration," Nature Biotechnology, vol. 18, no. 9, pp. 959-963, 2000.

[63] R. Schimming and R. Schmelzeisen, "Tissue-engineered bone for maxillary sinus augmentation," Journal of Oral and Maxillofacial Surgery, vol. 62, no. 6, pp. 724-729, 2004.

[64] M. Marcacci, E. Kon, V. Moukhachev et al., "Stem cells associated with macroporous bioceramics for long bone repair: 6-to 7-year outcome of a pilot clinical study," Tissue Engineering, vol. 13, no. 5, pp. 947-955, 2007.

[65] M. Chimutengwende-Gordon and W. S. Khan, "Advances in the use of stem cells and tissue engineering applications in bone repair," Current Stem Cell Research \& Therapy. In press.

[66] S. Gidado, W. S. Khan, and D. R. Marsh, "The effect of changes in oxygen tension during fracture repair on mesenchymal stem cell and bone activities," Current Research Journal of Biological Sciences, vol. 1, no. 1, pp. 7-10, 2009.

[67] E. G. Khaled, M. Saleh, S. Hindocha, M. Griffin, and W. S. Khan, "Tissue engineering for bone production- stem cells, gene therapy and scaffolds," Open Orthopaedics Journal, vol. 5, pp. 288-294, 2011.

[68] W. S. Khan, F. Rayanmarakkar, and D. R. Marsh, "Principles of tissue engineering approaches for bone repair in the hand," in Hand Surgery: Preoperative Expectations, Techniques and Results, R. H. Beckingsworth, Ed., pp. 71-84, Nova Science, New York, NY, USA, 2009.

[69] W. S. Khan and D. Marsh, "Tissue engineering approaches for bone repair: cells, scaffolds, growth factors and gene therapy," Stem Cell Research, vol. 2, no. 1, pp. 21-32, 2010.

[70] A. S. Shekkeris, P. K. Jaiswal, and W. S. Khan, "Clinical applications of mesenchymal stem cells in the treatment of fracture non-union and bone defects," Current Stem Cell Research \& Therapy. In press.

[71] B. A. Tucker, S. S. Karamsadkar, W. S. Khan, and P. Pastides, "The role of bone marrow derived mesenchymal stem cells in sports injuries," Journal of Stem Cells. In press.

[72] M. Kanitkar, H. D. Tailor, and W. S. Khan, "The use of growth factors and mesenchymal stem cells in orthopaedics," Open Orthopaedics Journal, vol. 5, pp. 268-274, 2011.

[73] L. Kennard, H. D. Tailor, G. Thanabalasundaram, and W. S. Khan, "Advances and developments in the use of human mesenchymal stem cells—a few considerations," Open Orthopaedics Journal, vol. 5, pp. 245-249, 2011.

[74] W. S. Khan, A. B. Adesida, S. R. Tew, J. G. Andrew, and T. E. Hardingham, "The epitope characterisation and the osteogenic differentiation potential of human fat pad-derived stem cells is maintained with ageing in later life," Injury, vol. 40, no. 2, pp. 150-157, 2009.

[75] W. S. Khan, A. A. Malik, and T. E. Hardingham, "Stem cell applications and tissue engineering approaches in surgical practice," Journal of perioperative practice, vol. 19, no. 4, pp. 130-135, 2009.

[76] W. S. Khan and D. R. Marsh, "A literature review on the effects of ageing on mesenchymal stem cells," Current Research Journal of Biological Sciences, vol. 1, no. 1, pp. 1-6, 2009.

[77] W. S. Khan, "Foreword: stem cell applications and tissue engineering approaches in sports medicine- from bench to bedside," Journal of Stem Cells. In press.

[78] P. Mafi, S. Hindocha, R. Mafi, M. Griffin, and W. S. Khan, "Sources of adult mesenchymal stem cells applicable for musculoskeletal applications- a systematic review of the literature," Open Orthopaedics Journal, vol. 5, pp. 238-244, 2011.

[79] P. Mafi, S. Hindocha, R. Mafi, M. Griffin, and W. S. Khan, "Adult mesenchymal stem cells and cell surface characterization- a systematic review of the literature," Open Orthopaedics Journal, vol. 5, pp. 250-257, 2011.

[80] A. Mahapatra and W. S. Khan, "Editorial: tissue engineering in orthopaedics and musculoskeletal sciences," Open Orthopaedics Journal, vol. 5, pp. 234-237, 2011.

[81] A. Malik and W. S. Khan, "Editorial: stem cell applications and tissue engineering approaches in orthopaedic surgery and musculoskeletal medicine," Current Stem Cell Research \& Therapy. In press.

[82] J. S. Mohal, H. D. Tailor, and W. S. Khan, "Sources of adult mesenchymal stem cells and their applicability for musculoskeletal applications," Current Stem Cell Research \& Therapy. In press.

[83] M. Nannaparaju, E. Oragui, and W. S. Khan, "The role of stem cells, scaffolds and bioreactors in musculoskeletal tissue engineering," in Mesenchymal Stem Cells, Y. Xiao, Ed., Nova Science, New York, NY, USA, 2011.

[84] M. Nannaparaju, E. Oragui, and W. S. Khan, "Stem cells, scaffolds and bioreactors in orthopaedic tissue engineering," Stem Cell Research. In press.

[85] E. Oragui, M. Nannaparaju, and W. S. Khan, "The role of bioreactors in tissue engineering for musculoskeletal applications," Open Orthopaedics Journal, vol. 5, pp. 264-267, 2011.

[86] G. Thanabalasundaram, N. Arumalla, H. D. Tailor, and W. S. Khan, "Regulation of differentiation of mesenchymal stem cells into musculoskeletal cells," Current Stem Cell Research \& Therapy. In press. 

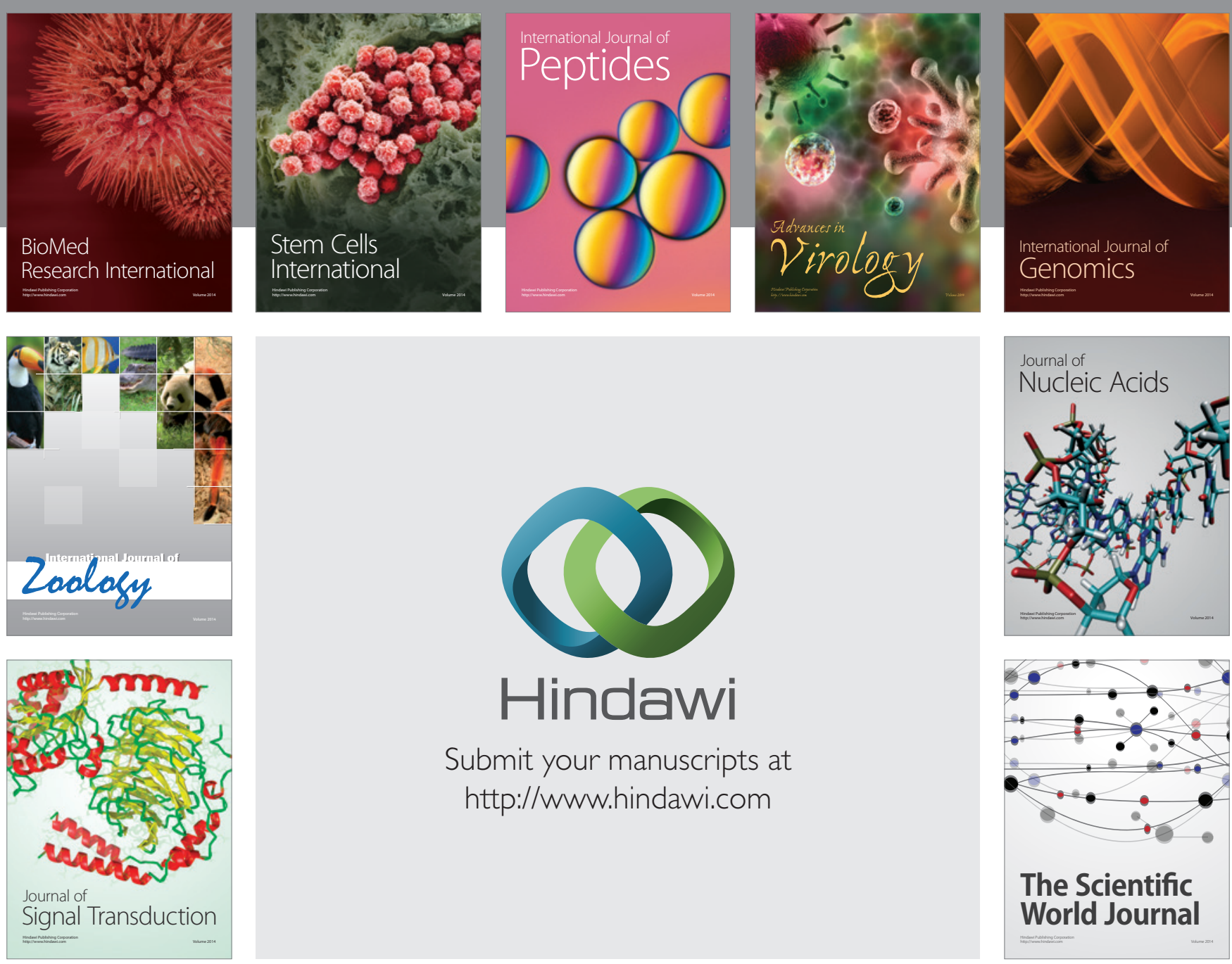

Submit your manuscripts at

http://www.hindawi.com
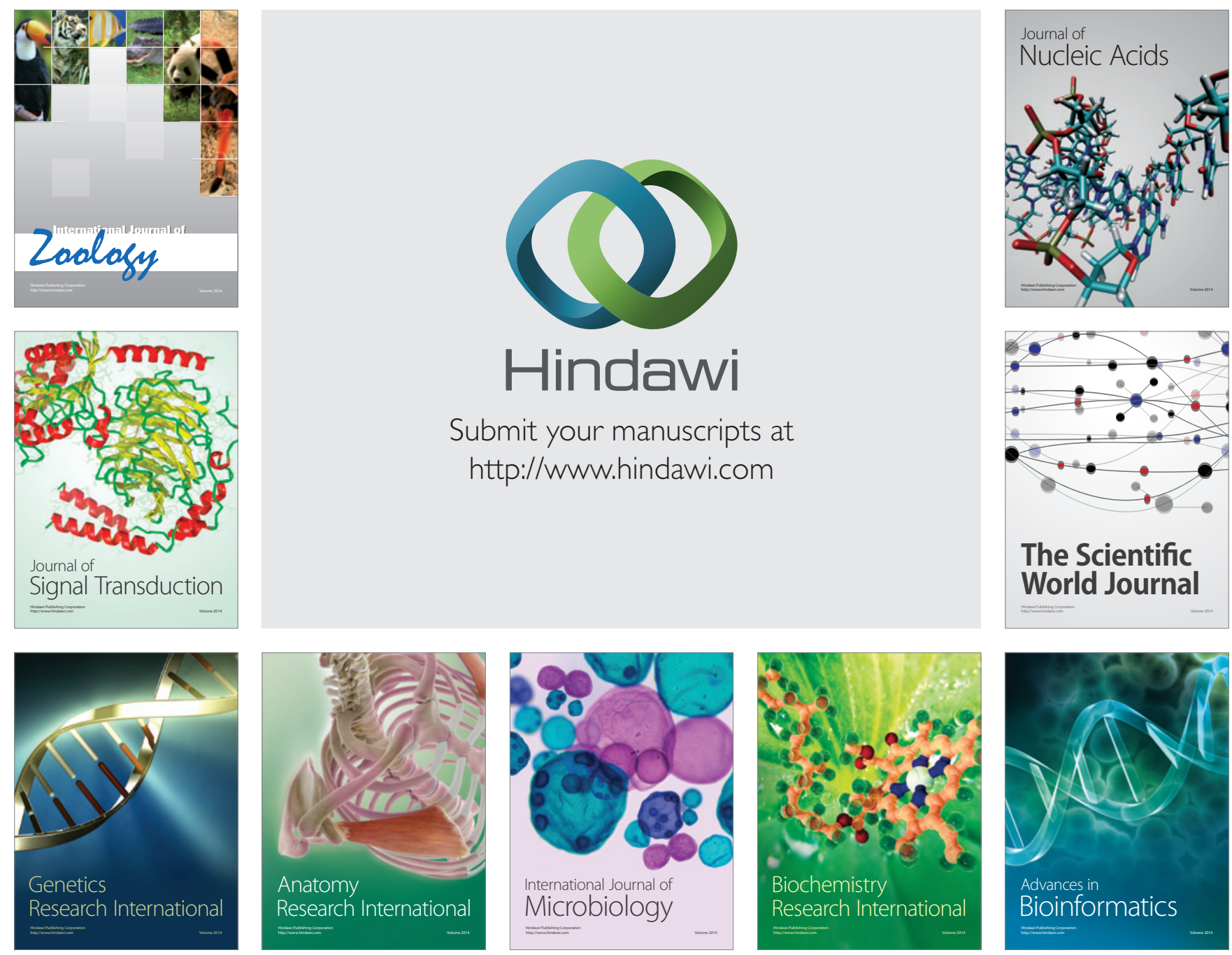

The Scientific World Journal
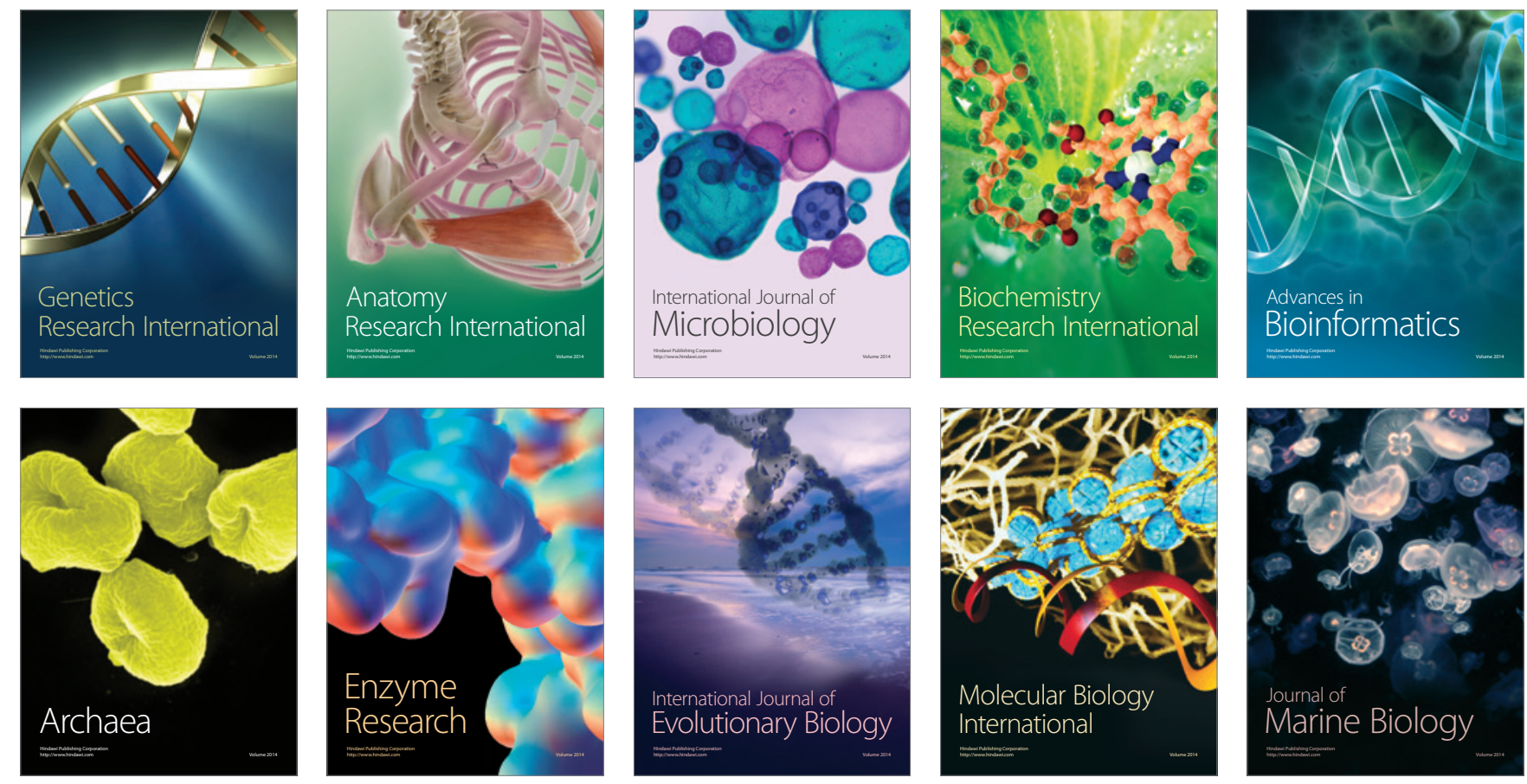